\title{
PERANCANGAN VIDEO TESTIMONI MIRACLE MALE AESTHETIC TREATMENT
}

\author{
Deli $^{1}$, Michael Jonathan ${ }^{2}$ \\ Universitas Internasional Batam, Universitas Internasional Batam \\ Universitas Internasional Batam \\ Jl. Gajah Mada, Sei. Ladi - Baloi, Batam \\ Delistan17@gmail.com¹, Mcdonald6788@gmail.com²
}

\begin{abstract}
Abstrak
Berdasarkan produk yang diproduksi untuk diperjual belikan kepada publik maka pengalaman yang dirasakan oleh pengguna atau penikmat produk memiliki kesan terhadap produk yang dikonsumsi dalam meningkatkan citra dari perusahaan itu sendiri oleh karenanya video testimoni merupakan salah satu cara untuk dapat memberikan sisi perspektif yang bersifat positif terhadap perusahaan dan dengan harapan bahwa dapat memberikan sentimen yang bisa mendukung kepercayaan pelanggan atau pengguna produk kepada masyarakat yang lebih luas terutama bagi mereka yang belum pernah menggunakan produk agar bisa mendapatkan gambaran atau keuntungan yang akan didapat dari penggunaan produk tersebut. Penyelesaian permasalahan yang dihadapi pada penelitian ini menggunakan metode Multimedia Development Life Cycle (MDLC) yaitu dengan tetap berfokus pada enam tahapan penyelesaian masalah pada pengembangan produk. Video dikemas dan didistribusikan melalui platform media sosial seperti instagram untuk menarik calon pelanggan baru di era yang modern ini dengan harapan agar produk yang ditawarkan oleh perusahaan dapat lebih dikenal oleh masyarakat luas.
\end{abstract}

Kata kunci :

Video Iklan, Video Testimoni, Video Komersil

\begin{abstract}
Based on products produced for sale to the public, the experience felt by users or product connoisseurs has an impression on the products consumed in improving the image of the company itself, therefore video testimonials are one way to be able to provide a positive perspective on the company and with the hope that it can provide a sentiment that can support
\end{abstract}

the trust of customers or product users to the wider community, especially for those who have never used the product in order to get an overview or benefit that will be obtained from using the product. Solving the problems faced in this study using the Multimedia Development Life Cycle (MDLC) method, namely by staying focused on the six stages of problem solving in product development. Videos are packaged and distributed through social media platforms such as Instagram to attract new potential customers in this modern era with the hope that the products offered by the company can be better known by the wider community.

Keywords :

Ads Video, Testimonial Video, Commercial Video.

\section{PENDAHULUAN}

Penerapan sinematografi memiliki dasar harfiah yang berasal dari Yunani cinema berasal dari kata kinema artinya gerakan dan graphy berasal dari kata graphoo yang artinya menulis. Sinematografi merupakan teknik pengambilan gambar yang terstruktur sedemikian rupa untuk memproduksi hasil gambar yang terkomposisi dan rapih dalam menyampaikan ide dan cerita yang telah dirancang dengan sedemikian rupa (Permata sari \& Abdullah, 2020).

Dalam lingkungan bisnis komersialisasi merupakan suatu kegiatan yang memungkinkan pembisnis atau pelaku usaha dari sesuatu yang diperdagangkan untuk mendapatkan keuntungan ataupun profit dari hasil kegiatan tersebut. Suatu kegiatan komersilal berjenis iklan yang secara terangterangan menawarkan jasa atau produk sebagai kegiatan pendukung dalam pemasaran yang lebih luas 
agar masyarakat dan dibuat sedemikian menarik guna mempengaruhi masyarakat untuk membeli suatu jasa atau produk tersebut (Saputra et al., 2020)

Sosial media merupakan wadah pendukung dalam pemasaran yang memiliki cakupan target pasar yang lebih luas lagi dan juga memudahkan dalam memasarkan suatu produk atau jasa agar memudahkan dalam penyaluran informasi pada masyarakat sebagai contoh media sosial Instagram (Semuel \& Setiawan, 2018)

Digital marketing adalah suatu kegiatan dalam memasarkan suatu produk atau jasa melalui semua platform via digital seperti mobile, web, online ads dengan adanya jenis pemasaran digital seperti ini dapat memudahkan pelaku usaha dan mengurangi biaya komisi penggunaan jasa pemasaran perorangan (Oktaviani \& Rustandi, 2018)

Miracle Aesthetic Clinic merupakan perusahaan yang berfokus dalam bidang perawatan dan kecantikan. Berlokasikan cabang di Batam tahun 2005 Miracle memiliki Visi menjadikan klinik estetika terpercaya dikawasannya dan juga menjadi salah satu klinik kepercayaan setempat, juga dengan Misi untuk membantu setiap orang mencapai penampilan terbaiknya. Miracle Aesthetic Clinic tidak hanya menargetkan wanita sebagai pelanggan utamanya. Miracle juga memperhatikan perawatan bagi kaum pria oleh karenanya Miracle ingin agar kaum pria merasa familiar dan tidak canggung dalam melakukan perawatan atau treatment. Oleh karena itu untuk mendukung rencana dalam pemasaran perawatan pada pria maka solusi dalam pembuatan video Miracle Male Aesthetic Treatment untuk memberikan pandangan kepada kaum pria bahwasannya perawatan tidak melulu hanya pada kaum wanita namun berlaku juga pada pria. Berdasarkan keterangan yang didapat penulis tertarik untuk mengangkat topik mengenai "perancangan video testimoni Male Aesthetic Treatment" untuk dapat memberikan pandangan kepada masyarakat terutama bagi kaum pria dalam melakukan treatment.

\section{TINJAUAN PUSTAKA}

Peran media sosial sangat penting sebagai instrumen untuk mempertemukan antara pembuat konten dan audience yang melihat dari konten tersebut dan juga untuk meningkatkan dan memudahkan intensitas komunikasi ataupun melakukan penyebaran berita atau informasi kepada audience terhadap sesuatu yang dijual ataupun dipamerkan menurut (Cahyono, 2016). Selain dari pada itu peran media sosial menurut (Supratman, 2018) juga dapat menjadi salah satu fokus pemilik usaha dalam melakukan eksplorasi interaksi pada audience.

Dengan kondisi pesatnya perkembangan arus teknologi dunia seperti saat ini telah memberikan dampak pada cara kerja bagi manusia terutama dalam penyampaian informasi, surat kabar, berita. Seperti contoh penggunaan internet sebagai media promosi dalam memberitakan tentang produk yang dijual (Tresnawati \& Prasetyo, 2018).

Penerapan teknik yang mumpuni juga dibutuhkan dalam mengambil gambar dengan menerapkan penggunaan teknik sinematografi pada proses pengambilan gambar berlangsung dapat menjadi acuan dalam melakukan pertimbangan atau pengarahan pada saat sedang mengkomposisikan gambar yang diambil yang mewakili makna dari setiap klip yang telah diambil (Sandy \& Sya'dian, 2020)

Multimedia merupakan istilah lain yang memiliki arti dari hadil gabungan antara lebih dari satu elemen kemudian mengkombinasikannya menjadi satu. Penerapan sistem multimedia tidak lain tidak bukan bertujuan untuk mempermudah pengguna dalam melakukan interaksi secara tidak langsung (Pradnaya Parata \& Zawawi, 2018). Multimedia juga dapat menjadi salah satu intrumen dalam memudahkan pelaku usaha untuk mengembangkan potensi dari bisnis agar dapat mencakup target pasar yang telah ditentukan.

Testimoni dibutuhkan dalam membangun
sebuah citra suatu perusahaan, kepuasan, kepercayaan, dan juga nilai dari suatu jasa atau juga produk. Testimoni bertujuan untuk mengumpulkan tanggapan atau kesan yang dirasakan agar dapat menjadi bukti kepuasan terhadap suatu layanan atau juga saran kepada pemilik usaha atau penyedia jasa (Maharani Jasmine \& Loen, 2020).

Jenis teknik shot pengambilan juga memiliki peran penting dalam memberikan dukungan penyajian gambar yang menarik dan membantu komunikasi visual dalam menceritakan suatu adegan maka dari itu teknik shot sangat penting perannya dalam menyampaikan informasi dengan baik (Permata sari \& Abdullah, 2020).
Deli, Michael Jonathan

Jurnal Ilmiah Teknologi Informasi Terapan

Volume 7, No 3, 15 Agustus 2021 
Berdasarkan hasil kajian dari penelitian sebelumnya, penulis merancang sebuah video yang berjudulkan proyek "Perancangan Video Testimoni Miracle Male Aesthetic Treatment" yang menjadi objek penelitian dimana proyek tersebut menerapkan teknik pengambilan gambar yang baik agar video dapat tersaji dengan layak oleh masyarakat yang menyaksikan. Kemudian hasil dari pada bentuk potongan klip aka digabungkan pada saat proses editing penulis menggunakan software Adobe Premiere Pro dengan penyuguhan konten yang berkaitan dengan tema yang diusung oleh penulis. Setelahnya konten akan di publikasikan ke Instagram untuk dapat dilihat oleh pelanggan lama ataupun bagi pengunjung baru.

\section{II.1 Landasan Teori}

Menjadi acuan bagi penulis dalam pemahaman dari judul yang penulis bawa dan menjadi suatu landasan dalam mengkaji lebih dalam. Berisikan kajian teori berupa beberapa penjelasan yang memiliki kaitan yang difokuskan oleh penulis.

1. Iklan, merupakan bentuk sebuah tayangan yang didistribusi berupa gambar, video, ataupun suara seperti radio dengan tujuan untuk memberikan seputar informasi produk atau jasa agar mendapat perhatian dari masyarakat. (Kumalaningtyas \& Sadasri, 2018).

2. Multimedia, merupakan suatu instrument dari penggabungan lebih dari satu bagian yang umumnya penggabungan antara teks, gambar, suara, animasi, dan video (Prima Kurniawati et al., 2018). Multimedia memiliki 3 jenis (Bilal \& Saputro, 2019) yaitu Multimedia Interaktif; Multimedia Hiperaktif dan Multimedia Linear.

\section{II.2 Sinematografi}

Sinematografi adalah hal-hal yang mempelajari soal tata cara mengambil dan menggabungkan serangkaian gambar menjadi cerita yang utuh. Sehingga dari hasil gambar yang yang telah di rangkai tersebut dapat berfungsi sebagai media pemberi suatu informasi maupun gagasan pesan (Sulistiyawati et al., 2019).

Dalam tahapan proses produksi suatu film membutuhkan beberapa tahapan prosedur diantaranya terdiri dari tiga tahapan diantaranya adalah (Fadli Yanuar Lubis \& Wahyuni, 2020), Pra Produksi; Produksi dan Paska Produksi.

\section{METODE PENELITIAN}

\section{III.1 Metode Perancangan}

Pada proses pelaksanaannya penulis menggunakan metode penelitian dengan menggunakan metode multimedia development life cycle. Pada tahapannya multimedia development life cycle terdiri dai enam langkah tahapan atau langkah menurut (Karundeng et al., 2018) yaitu, Concept; Design; Material Collecting; Assembly; Testing dan Distribution.

\section{III.2 Analisa Permasalahan}

Penggunaan media video merupakan media audio vidual dalam menyampaikan pesan. Dapat berfungsi menjadi ciri-ciri pengenal pada sebuah perusahaan atu juga bisa pada lembaga. Video berisi tentang seputar informasi perihal fasilitas pelayanan yang diberikan untuk pengunjung terutama untuk perawatan bagi pria dengan tujuan agar kaum pria tidak melulu memiliki pandangan bahwa perawatan hanya untuk wanita saja akan tetapi pria juga bisa melakukan perawatan.

\section{III.3 Perancangan Video}

Pada proses perancangannya penulis menggunakan terapan jenis sinematografi seperti berikut ini:

1. Konsep, Pengerjaan konsep video testimoni memiliki konsep seperti video iklan pada umumnya yakni menyelipkan adegan pengalaman yang dirasakan setelah merasakan hasil yang diberikan dari sisi fitur pelayanan yang diberikan kepada pelanggan, sehingga dapat menciptakan daya tarik bagi penonton untuk dapat mencoba dari produk yang dimili oleh perusahaan tersebut.

2. Design, Pada tahap proses design penulis melakukan proses penyusunan langkah dalam melakukan pembuatan video. Storyboard sendiri merupakan gambaran kasar yang dibuat untuk menjadi acuan untuk memudahkan penulis dalam melaksanakan proses produksi (Ansoriyah \& Rahmat, 2018). 


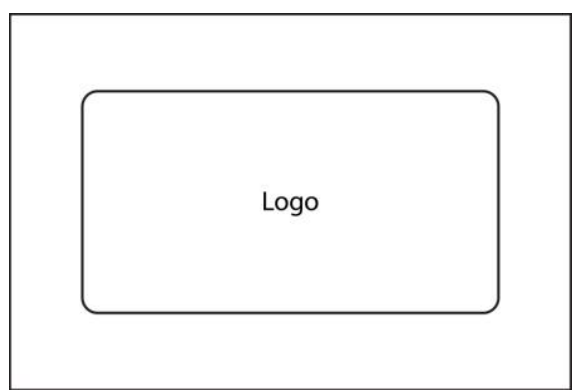

Gambar 3.1 Animasi Logo Pembukaan Video

Pada gambar 3.1 penulis membuat sebuah video pembukaan yang mempunyai tujuan ketika masuk pada video inti penonton tidak dikejutkan secara mendadak.

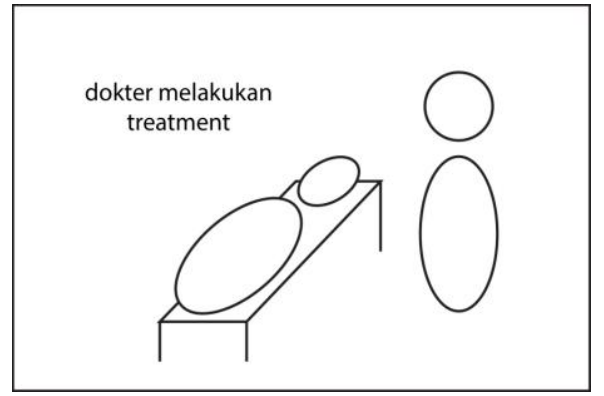

Gambar 3.2 Proses Dokter Melakukan Treatment

Pada gambar 3.2 terlihat bahwa penulis tengah mengilustrasikan bagaimana suasana yang tengah berlangsung saat dokter tengah melakukan proses treatment.

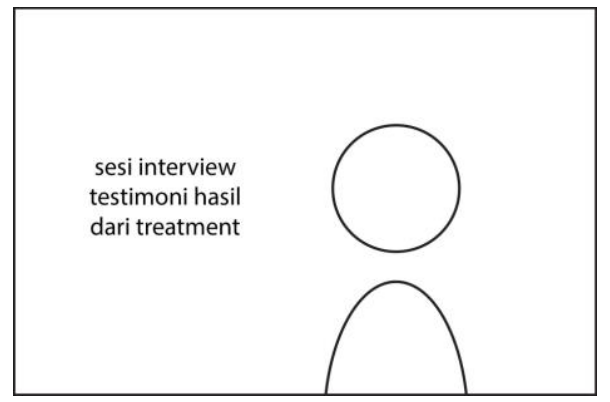

Gambar 3.3 Sesi Interview Testimonial Produk

Pada gambar 3.3 menggambarkan bagaimana perasaan yang dirasakan oleh pelanggan dari hasil treatment yang diterima dalam bentuk sesi interview kepuasan pelanggan.

3. Pengumpulan Data, Tahapan metode pengumpulan data video yakni melalui tahapan metode observasi. Metode ini merupakan teknik dalam mengumpulkan informasi dengan cara langsung mendatangi lokasi tempat yang akan ditinjau.

4. Proses Pengerjaan, Di dalam proses pengerjaan video Penulis menggunakan beberapa software seperti adobe premiere pro untuk menyatukan klip dan adobe after effect untuk membuat animasi pada tulisan.

\section{IMPLEMENTASI}

\section{IV.1 Implementasi}

Proyek implementasi yang tengah penulis kerjakan disusun dengan menggunakan perangkat lunak dari Adobe Premiere Pro. Video di susun dengan pendek untuk dapat menyampaikan informasi singkat padat dan jelas pada sisial media. Penulis mengusung media sosial dari Instagram karena mayoritas masyarakat dunia saat ini lebih menyukai sesuatu yang bersifat mobilitas.

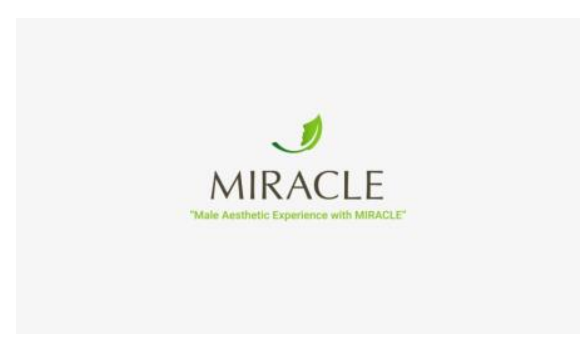

\section{Gambar 4.1 Pembukaan Animasi Video}

Video dibuka dengan animasi logo perusahaan sebelum konten video utama masuk memberikan sisi perkenalan perusahaan kepada penonton.

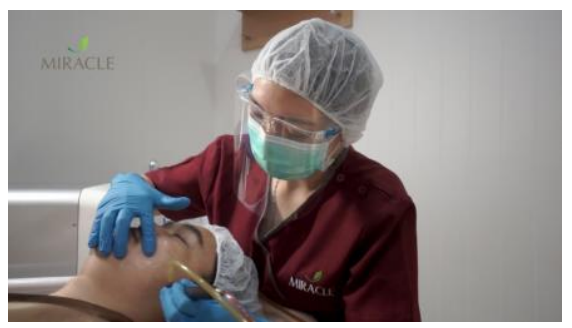

Gambar 4.2 Potongan Klip Prosesi Treatment

Pada gambat 4.2 terlihat bahwa klip menunjukkan bagaimana sedang berlangsung sesi prosesi treatment kepada salah satu pelanggan yang diperagakan oleh model.
Deli, Michael Jonathan

Jurnal Ilmiah Teknologi Informasi Terapan

Volume 7, No 3, 15 Agustus 2021 


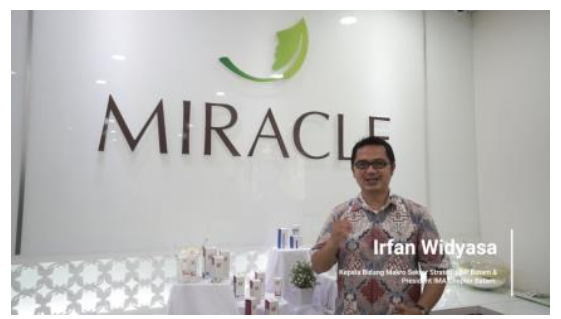

Gambar 4.3 Klip Sesi Interview

Setelah menjalani prosesi treatment dari dokter pelanggan memberikan hasil testimoni yang dirasakan dari treatment yang didapatkan.

\section{IV.2 Implikasi}

Penggunaan media video merupakan media audio vidual dalam menyampaikan pesan. Dapat berfungsi menjadi ciri-ciri pengenal pada sebuah perusahaan atu juga bisa pada lembaga. Video berisi tentang seputar informasi perihal fasilitas pelayanan yang diberikan untuk pengunjung terutama untuk perawatan bagi pria dengan tujuan agar kaum pria tidak melulu memiliki pandangan bahwa perawatan hanya untuk wanita saja akan tetapi pria juga bisa melakukan perawatan.

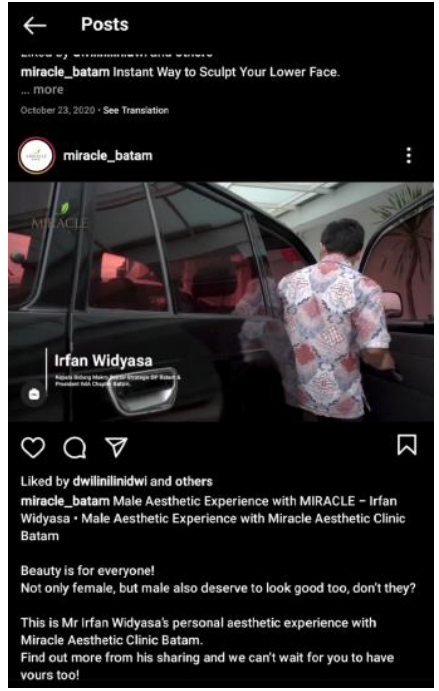

Gambar 4.1 Bukti Implementasi Proyek Pada Media Sosial Instagram

Hasil dari pada proyek video testimoni telah diunggah pada tanggal 22 Oktober 2020 pada halaman diding postingan akun Instagram milik dari perusahaan Miracle Aesthetic Clinic Batam.

\section{PENUTUP}

\section{V.1 Kesimpulan}

Dibawah ini merupakan bentuk kesimpulan hasil dari proyek "Perancangan Video Testimoni Miracle Male Aesthetic Treatment" sebagai berikut:

1. Hasil akhir dari "Perancangan Video Testimoni Miracle Male Aesthetic Treatment" disusun dengan mengemas informasi seputar pengalaman yang dirasakan oleh narasumber yang dibagikan kepada public untuk mendapatkan rasa percaya kepada perusahaan yang melakukan praktik.

2. Bentuk validasi pengerjaan proyek telah disetujuinya untuk dapat diunggah menggunakan media sosial Instagram, yang digunakan sebagai bentuk memudahkan proses distribusi informasi kepada publik.

3. Video dikerjakan dengan menerapkan metode Multimedia Development Life Cicle memberikan dampak positif dalam mencari referensi dalam mengerjakan proyek.

4. Peralatan yang digunakan saat melakukan shooting menggunakan kamera sony a6000 dan canon kiss $x 5$ dengan menggunakan stabilizer dari dji ronin s.

\section{V.2 Saran}

Terdapat beberapa saran yang didapat dari proses "PERANCANGAN VIDEO TESTIMONI MIRACLE MALE AESTHETIC TREATMENT" sebaai berikut:

1. Lebih memperhatikan situasi lingkungan agar memudahkan dalam merancang video dilokasi saat proses pengambilan gambar sedang berlangsung.

2. Lebih atraktif lagi dalam menyajikan seputaran informasi penting terkait yang dimiliki oleh perusahaan untuk menjual produk atau jasanya kepada masyarakat.

3. Lebih memperhatikan lagi dan mempertimbangkan kembali dengan matang jenis teknik shot yang akan digunakan dalam melakukan pengambilan gambar dan juga tidak lupa dalam mempertimbangkan movement, angle, dan setingan kamera yang tepat pada lingkungannya, beserta mempersiapkan kelengkapan alat yang dibutuhkan dalam mengerjakan proyek.
Deli, Michael Jonathan

Jurnal Ilmiah Teknologi Informasi Terapan

Volume 7, No 3, 15 Agustus 2021 


\section{DAFTAR PUSTAKA}

Ansoriyah, S., \& Rahmat, A. (2018). Peningkatan Kemampuan Menulis Populer Mahasiswa Melalui Pendekatan Whole Language Dengan Pembuatan Media Story Board. 2(1), 29-46.

Bilal, A. M., \& Saputro, A. (2019). Implementasi Multimedia Pembelajaran Interaktif Pengenalan Tata Surya Pada Kelas 3 Sampai kelas 5 SDN Pasar Baru 07 Pagi. Idealis, 2(4), 147-153.

Cahyono, A. S. (2016). Pengaruh media sosial terhadap perubahan sosial masyarakat di Indonesia. 9(1), 140-157.

Cavenett. (2013). 済無No Title No Title. Journal of Chemical Information and Modeling, 53(9), 1689-1699.

https://doi.org/10.1017/CBO9781107415324.00 4

Fadli Yanuar Lubis, M., \& Wahyuni, S. (2020). Penerapan sinematografi pada film pilar. 1(1), 438-450.

Karundeng, C. O., Mamahit, D. J., \& Sugiarso, B. A. (2018). Rancang Bangun Aplikasi Pengenalan Satwa Langka di Indonesia Menggunakan Augmented Reality. 14(1), 1-8.

Kumalaningtyas, N., \& Sadasri, L. M. (2018). Citra Tubuh Positif Perempuan Dalam Iklan Video Digital (Studi Femvertising Pada Iklan Dove Real Beauty). Diakom: Jurnal Media Dan Komunikasi, 1(2), 62-73. https://doi.org/10.17933/diakom.v1i2.19

Maharani Jasmine, A., \& Loen, R. B. (2020). Penggunaan Video Company Profile sebagai Sarana Informasi dan Meningkatkan Promosi pada PT Avoir Industry. JTIM: Jurnal Teknologi Informasi Dan Multimedia, 2(2), 125-132. https://doi.org/10.35746/jtim.v2i2.100

Oktaviani, F., \& Rustandi, D. (2018). Implementasi Digital Marketing dalam Membangun Brand Awareness. 3(1), 1-20.

Permata sari, R., \& Abdullah, A. (2020). Analisis Isi Penerapan Teknik Sinematografi Videoklip Monokrom. 2(1), 44-55.

Pradnaya Parata, T., \& Zawawi, M. (2018). Pemanfaatan Multimedia Interaktif Pembelajaran Ipa-Biologi Terhadap Motivasi Dan Kemampuan Kognitif Siswa Smp Negeri 14
Kota Palembang. 3(2), 139-166.

Prima Kurniawati, R., Rahmantika Hadi, F., \& Rulviana, V. (2018). Pengembangan Multimedia Pembelajaran Berbasis Cognitive Load Theory (Clt) Pada Materi Volume Kubus Dan Balok Di Sekolah Dasar. 7(2), 314-323.

Sandy, A. S., \& Sya'dian, T. (2020). Analisis Sinematografi Program Edisi Ada Gula, Ada Sejahtera Di Daai Tv Sumut. Mahasiswa Fakultas Seni Dan Desain, 1(1), 329-340. Http://E-Journal.Potensi-

Utama.Ac.Id/Ojs/Index.Php/Fsd/Article/View/7 27

Saputra, D. I. S., Udianti, A., Rosyidi, R., \& Berlilana, B. (2020). Creativepreneur: Optimalisasi Produk Animasi "Simbah" Dalam Komersialisasi Kekayaan Intelektual. 10(1), 32-42.

Https://Doi.Org/10.26594/Teknologi.V10i1.201

Semuel, H., \& Setiawan, K. Y. (2018). Promosi Melalui Sosial Media , Brand Awareness, Purchase. Manajemen Pemasaran, 12(1), 4752. Https://Doi.Org/10.9744/Pemasaran.12.1.47

Sulistiyawati, P., Irawan Ihya, D., \& Ulumuddin. (2019). Analisis Komponen Visual Dasar Sinematografi Dalam Film Live Action "Green Book. " 04(2), 172-198.

Supratman, L. P. (2018). Penggunaan Media Sosial Oleh Digital Native. Jurnal Ilmu Komunikasi, 15(1), 47-60. Https://Doi.Org/10.24002/Jik.V15i1.1243

Tresnawati, Y., \& Prasetyo, K. (2018). Pemetaan Konten Promosi Digital Bisnis Kuliner Kika's Catering Di Media Sosial. Profesi Humas: Jurnal Ilmiah Ilmu Hubungan Masyarakat, 3(1), 102.

Deli, Michael Jonathan 